\title{
OPTIMIZATION OF RUNOFF PARAMETERS OF A WATERSHED BY GENETIC ALGORITHM AND VISUALIZING THE RUNOFF IN 4D GIS ENVIRONMENT
}

\author{
Himanshu Panwar ${ }^{1}$, K. Venkata Reddy ${ }^{2}$ \\ ${ }^{1}$ Assistant Professor, Civil Engineering Department N.I.E.C. New Delhi \\ himanshu1105@gmail.com \\ ${ }^{2}$ Assistant Professor, Civil Engineering Department NIT Warangal, Telangana \\ kvreddy@nitw.ac.in
}

\begin{abstract}
The Genetic Algorithm has been integrated with Finite Element Method (FEM) based distributed rainfall runoff model. It optimizes the four parameters i.e. saturated hydraulic conductivity, initial water content, suction head and saturated water content which generates the simulated runoff, which is then compared with the observed runoff data of actual site. The model has been applied to Harsul watershed located in Nashik district of Maharashtra, India. The objective function used in Genetic Algorithm is Nash-Sutcliffe Model Efficiency Constant objective function, and this combination produced good results. It performed well for many rainfall events except for those which have high rainfall intensity and low runoff. The Genetic Algorithm proved to be capable and robust in terms of maximising the objective function. Within 50 generations of 10 populations each, it has provided satisfactory results. GIS has been used to prepare all the thematic maps of the study area. The simulated runoff data generated from the model has been imported to GIS environment where it is visualized dynamically in $3 D$ format with time series animation. The methodology developed in the present study can be used to simulate flow parameters of watershed.
\end{abstract}

Keywords: FEM based distributed rainfall-runoff model, Genetic Algorithm, Nash-Sutcliffe Model Efficiency Constant, 4D GIS animation.

\section{INTRODUCTION}

In India, around $60 \%$ of the cultivated area is rain-fed. On the other hand the population is also rising every year which in turn generating a huge demand of fresh water supply. Hence in order to fulfil these demands, watersheds are playing a vital role. In order to monitor these watersheds closely and to make wiser decisions, it is very important to estimate the rainfall and runoff within these watersheds accurately. Nowdays, various conceptual rainfall-runoff models have been developed and with the involvement of soft-computing techniques like Genetic Algorithm (GA), Artificial Neural Network (ANN), Fuzzy logic etc. These intelligent methods, using potential knowledge therein available data, develop general relations between these data and adopt these relations within other conditions (Nourani, 2008). A comparative study of various objective functions used in a runoff model is discussed by Servat and Alain (1991). Agarwal et al. (2003) discussed about using of Genetic Algorithm for estimation of parameters of a runoff prediction model which was tested for 700 generations. The main component of the model is the objective function which compares the observed runoff data with generated simulated runoff. The quality of the calibration of parameters depends upon the objective function used.

Remote sensing and GIS are playing an important role in the field of hydrology and water resources development. Remote sensing provides the spatial and temporal data of the site which is important for hydrological modelling of the area and with the help of GIS technology, these spatial database could be managed and visualized in $2 \mathrm{D}$ and $3 \mathrm{D}$ format with timeseries animation which is helpful in prediction in more realistic way. In the present study, an attempt has been made to integrate a Finite Element Method (FEM) based distributed rainfall runoff model (Reddy et al, 2007) with Genetic Algorithm and to employ Geographical Information System (GIS) to handle the heterogeneity in the geographic characteristics within basin. Moreover, visualize the runoff dynamically in 3D GIS environment for each and every element of the basin and its variation with respect to time.

\section{DATABASE AND SOFTWARES}

The various database and software used in this study are:-

1. Finite Element Method (FEM) based distributed rainfallrunoff model (written in C language) by Reddy et al. (2011).

2. Geospatial layers for the study area (Reddy et al., 2011)

3. Simple Genetic Algorithm (SGA) developed by Prof. Deb, source code (written in C language) is from Genetic Algorithm laboratory, Indian Institute of Technology, Kanpur.

4. Microsoft Visual Studio 2012

5. ESRI ArcScene for creating 3D visualization of flow and time series animation. 


\section{METHODOLOGY}

Methodology has been developed to integrate FEM based rainfall runoff model, Genetic Algorithm (GA) and GIS for simulation and visualization of runoff (Figure 1). When integrated model starts, the user have to first insert the data for various parameters in

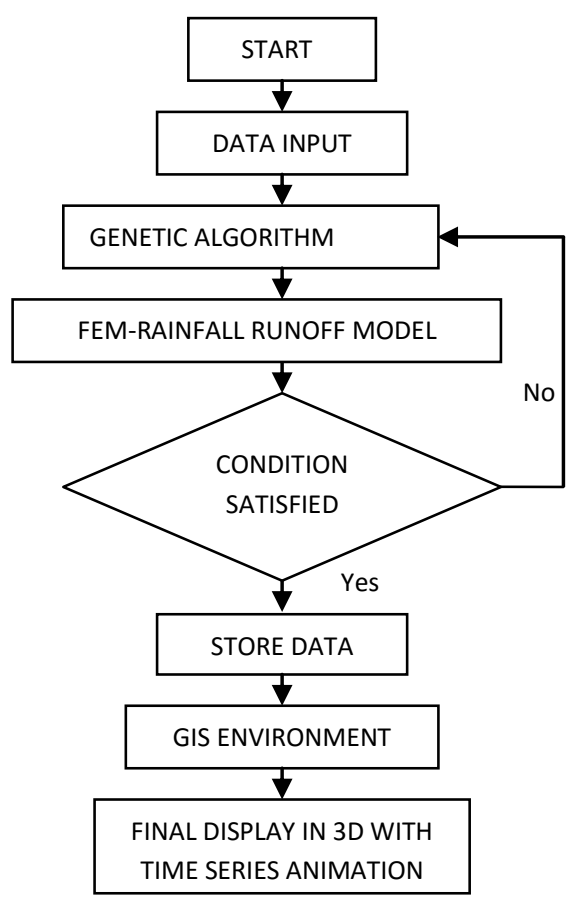

Figure 1: Methodology flowchart

rainfall model including observed runoff data and then parameters for GA i.e. number of generations and population etc. After receiving parameters, GA starts generating random variables which act as inputs for runoff simulation. The simulated runoff data generated from runoff model is compared with observed runoff data within the program and then it produces a fitness value. If the fitness value matches with the desired fitness value which user enters at the beginning of the program, it will stop and the data will get stored in the text files otherwise it will continue. The data is then imported into GIS environment for 3D visual display and its time series animation.

\section{OBJECTIVE FUNCTION}

The objective function adopted in the GA model is NashSutcliffe Model Efficiency Constant (Servat and Alain, 1991)).The formulation has shown below:

$$
f(x)=1-\left[\sum_{i=0}^{n}\left(Q_{c}-Q_{o}\right) 2 / \sum_{i=0}^{n}\left(Q_{o}-Q_{m o}\right)^{2}\right](1)
$$

Where:

$\mathrm{Q}_{\mathrm{c}} \quad=$ Simulated runoff, $\mathrm{Q}_{\mathrm{o}}=$ Observed runoff

$\mathrm{Q}_{\mathrm{mo}}=$ Observed mean runoff $\mathrm{n}$

$$
=\text { Last time value of observed runoff }
$$

\section{FITNESS FUNCTION}

The objective function is maximized in order to get the fittest values. To avoid the generation of negative numbers, the mapping of objective function into fitness function is carried out as follows:

$$
\mathrm{F}(\mathrm{x})=\frac{1}{(1+\mathrm{f}(\mathrm{x}))}
$$

Here, the objective function is modified as shown below:

$$
f(x)=\left[\sum_{i=0}^{n}\left(Q_{c}-Q_{o}\right) 2 / \sum_{i=0}^{n}\left(Q_{o}-Q_{m o}\right)^{2}\right]
$$

This expression tends towards 0 when $Q_{c}$ tends towards $Q_{o}$.

\section{MODEL APPLICATION}

The integrated model has been applied to Harsul watershed located in the Nashik district of Maharashtra, India. It is situated between East Longitudes of $73^{\circ} 25^{\prime}$ and $73^{\circ} 29^{\prime}$ and North Latitudes of $20^{\circ} 04^{\prime}$ and $20^{\circ} 08^{\prime}$ (Figure 2) covering an area of $10.929 \mathrm{Km} 2$.The dominant flow direction of surface runoff is towards North. Major soil type in the watershed is gravelly loam.

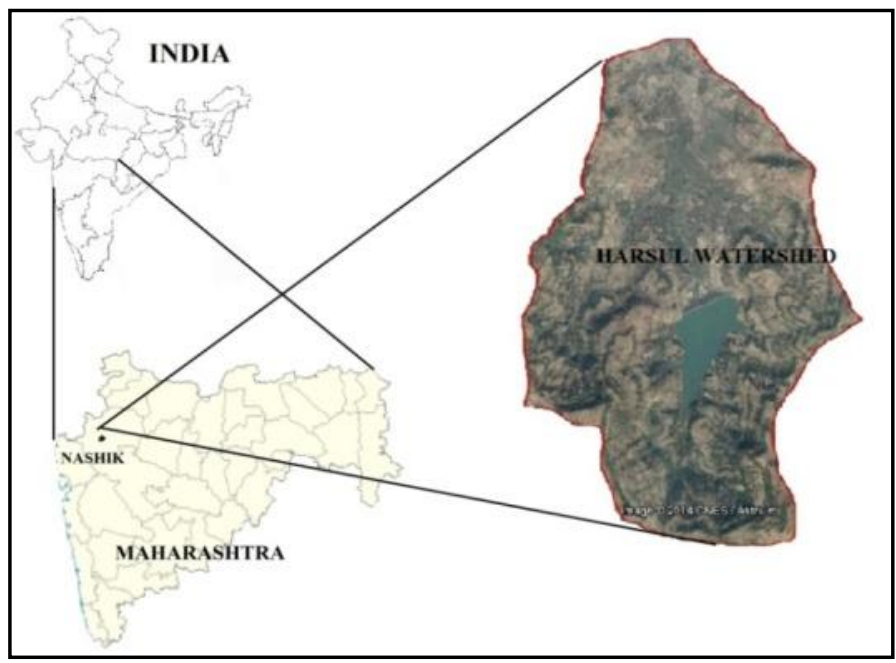

Figure 2: Location map of Harsul watershed

The slope map, Land Use and Land Cover (LU/LC), drainage network map and FEM grid map have shown in Figure 3 (Database source: Reddy et al. 2011). The slope map is prepared from Digital Elevation Model. Remotely sensed data of IRS 1D LISS III imagery of January 13, 1998 has been used to extract LU/LC of the watershed. LU/LC classes identified are agricultural land (49.55\%), forest land (43.22\%) and waste land $(7.03 \%)$. Manning's roughness value (overland flow) assigned as 0.015 . The grid map of the watershed is discretized into overland flow strips which are connected to 1 discretized channel. There are total 168 overland flow elements, 232 overland flow nodes and 32 channel flow elements.

This equation tends towards 1 when $Q_{c}$ tends towards $Q_{o}$. 


\section{RESULTS AND DISCUSSIONS}

The integrated model is tested for six rainfall events from July to August 1997. Calibration is carried out for 4 infiltration parameters i.e. saturated hydraulic conductivity, initial water content, saturated water content and suction head. The model has run for 55 generations of 10 populations each, thereby a total of 550 cycles. The initial range that has been assigned to each infiltration parameter for a particular rainfall event is shown in Table 1.
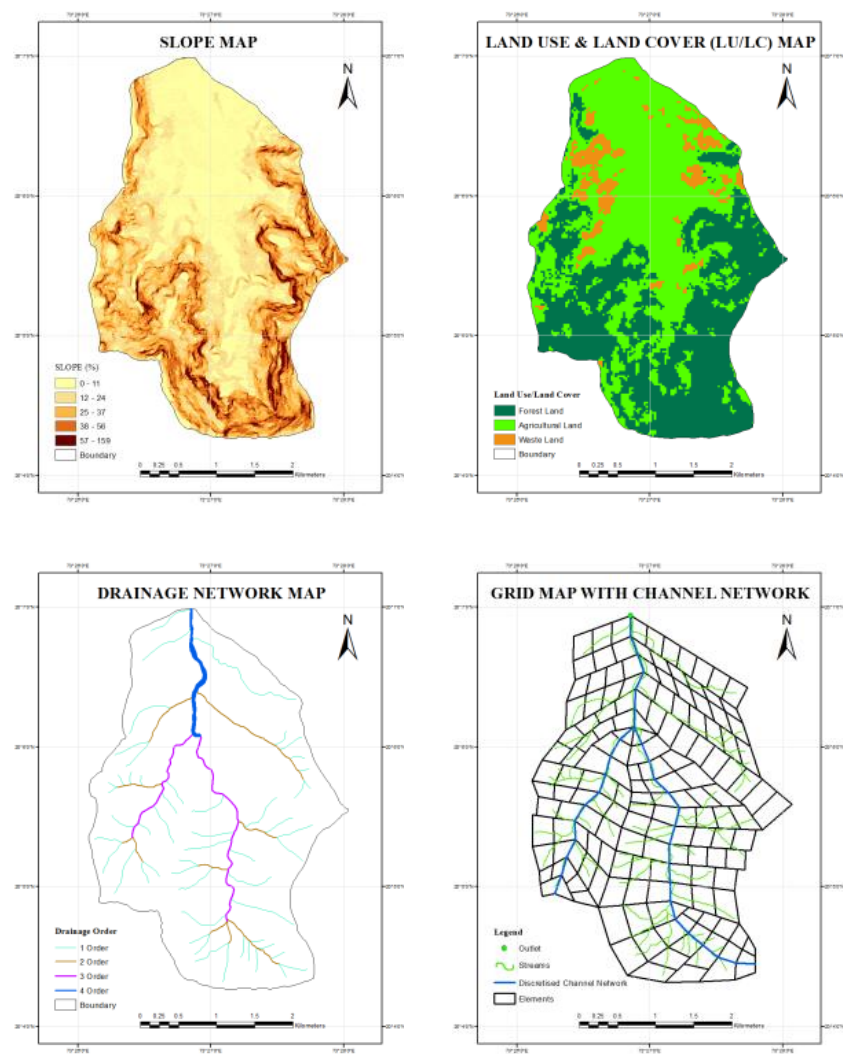

The observed and simulated hydrographs for all the six rainfall events are shown in Figure 4. The calibrated infiltration parameters for all rainfall events are shown in Table 2. Apart from comparing hydrographs, the percentage variations of the simulated and observed runoff data in terms of cumulative runoff, peak runoff and time to peak runoff were calculated as shown in Table 3 . For all the calibrated events, it is seen that the percentage variations of volume of runoff is with $5 \%$ to $86 \%$. The percentage variation in terms of peak runoff is mostly high. The minimum variation achieved is $1 \%$ and the maximum reached upto $86 \%$. The percentage runoffs in terms of time to peak runoff are within $0 \%$ to maximum $77 \%$.

In all the rainfall events, the overall shape of the hydrographs of simulated and observed runoff data are almost same except for the event of 26th July 1997 which shows a moderate variation in the shape of initial part simulated runoff hydrograph.

\section{4D Visualization of Runoff}

In $4 \mathrm{D}$ visualization of runoff, the runoff can be visualized dynamically with respect to time for each and every grid element of the watershed. In water resource field, the use of 4D GIS can enable the researches and scientists to understand the complex interaction within the watershed in visual form. The simulated data stored is imported to GIS software ArcMap where data is converted into time order with the use of tools like transpose and convert time field tool stored in the database management toolbox. Then converted data is connected with the shape file. The time is enabled in the shape file from time tab in layer properties and the $4 \mathrm{D}$ visualization can be seen in ArcScene by using time slider. The time series animation at different time interval is shown in Figure 5.

Figure 3: Slope, LU/LC, Drainage network and Grid map of the watershed (Source: Reddy el al., 2011).

Table 1: Initial ranges of infiltration parameters.

\begin{tabular}{|c|c|c|c|c|}
\hline Date of rainfall & $\begin{array}{c}\text { Saturated hydraulic conductivity } \\
\mathrm{Ks}(\mathrm{cm} / \mathrm{hr})\end{array}$ & $\begin{array}{c}\text { Suction head } \\
(\mathrm{sav})(\mathrm{cm})\end{array}$ & $\begin{array}{c}\text { Saturated water } \\
\text { content }(\theta \mathrm{i})\end{array}$ & $\begin{array}{c}\text { Initial water content } \\
(\theta \mathrm{i})\end{array}$ \\
\hline July 26,1997 & $0.4-0.5$ & $0.13-0.15$ & $0.42-0.45$ & $0.3-0.4$ \\
\hline July 27,1997 & $0.4-0.5$ & $0.13-0.15$ & $0.42-0.46$ & $0.3-0.5$ \\
\hline August 4,1997 & $0.3-0.5$ & $3.00-5.00$ & $0.41-0.46$ & $0.3-0.4$ \\
\hline August 21,1997 & $0.3-0.5$ & $3.00-5.00$ & $0.41-0.46$ & $0.3-0.4$ \\
\hline August 22,1997 & $0.4-0.5$ & $0.13-0.15$ & $0.42-0.45$ & $0.3-0.5$ \\
\hline August 23,1997 & $0.4-0.5$ & $0.13-0.15$ & $0.42-0.46$ & \\
\hline
\end{tabular}


Table 2: Calibrated GAML infiltration parameters for rainfall events of Harsul watershed

\begin{tabular}{|c|c|c|c|c|}
\hline Date of rainfall & $\begin{array}{c}\text { Saturated hydraulic } \\
\text { conductivity Ks(cm/hr) }\end{array}$ & $\begin{array}{c}\text { Suction head } \\
(\mathrm{sav})(\mathrm{cm})\end{array}$ & $\begin{array}{c}\text { Saturated water } \\
\text { content }(\theta \mathrm{i})\end{array}$ & $\begin{array}{c}\text { Initial water } \\
\text { content }(\theta \mathrm{i})\end{array}$ \\
\hline July 26,1997 & 0.49 & 0.13 & 0.44 & 0.360 \\
\hline July 27,1997 & 0.42 & 0.13 & 0.45 & 0.450 \\
\hline August 4,1997 & 0.42 & 3.00 & 0.44 & 0.360 \\
\hline August 21,1997 & 0.47 & 4.73 & 0.42 & 0.360 \\
\hline August 22,1997 & 0.49 & 0.13 & 0.42 & 0.393 \\
\hline August 23,1997 & 0.43 & 0.13 & 0.42 & 0.306 \\
\hline
\end{tabular}

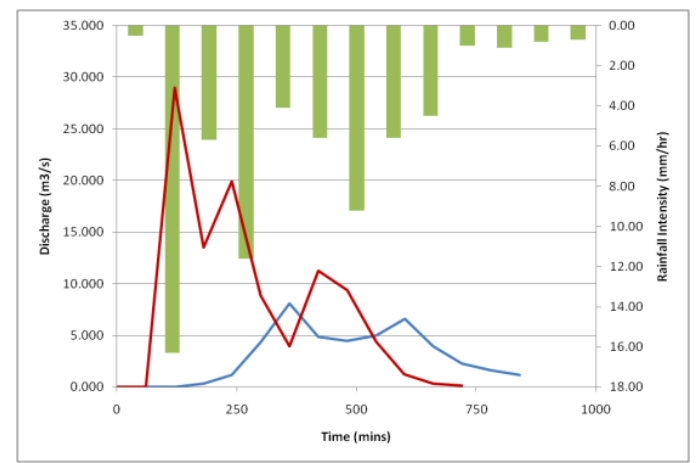

(a)

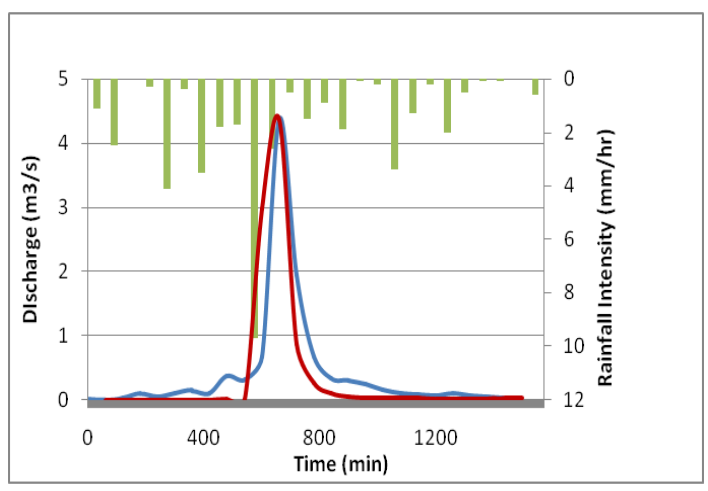

(c)

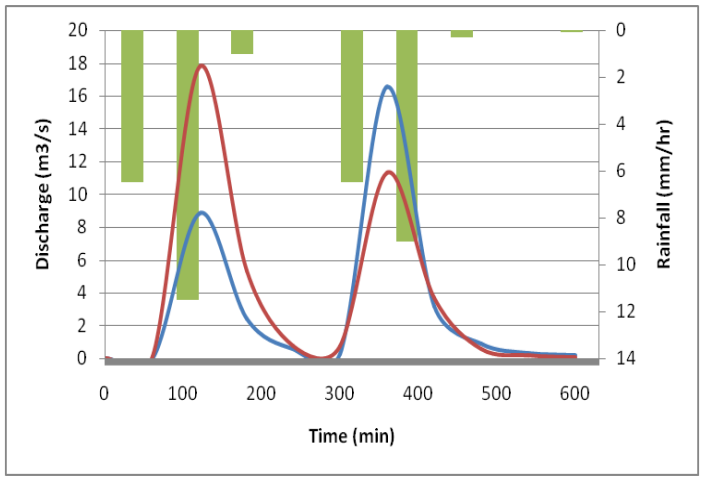

(e)

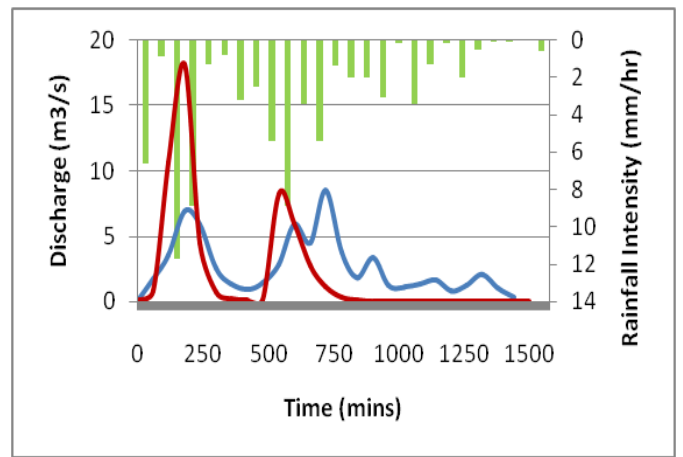

(b)

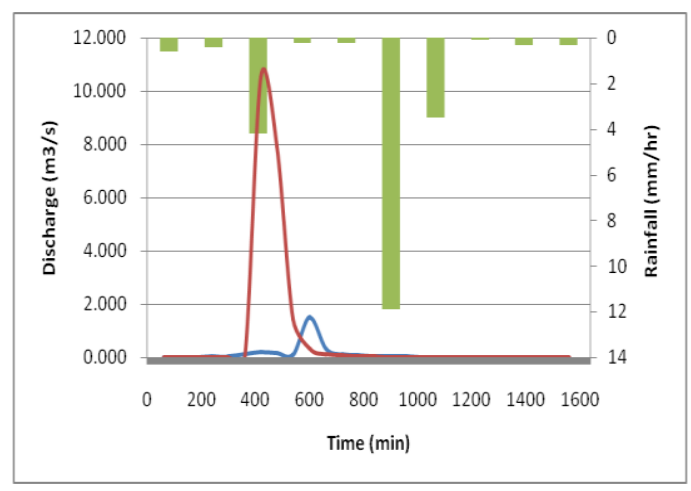

(d)

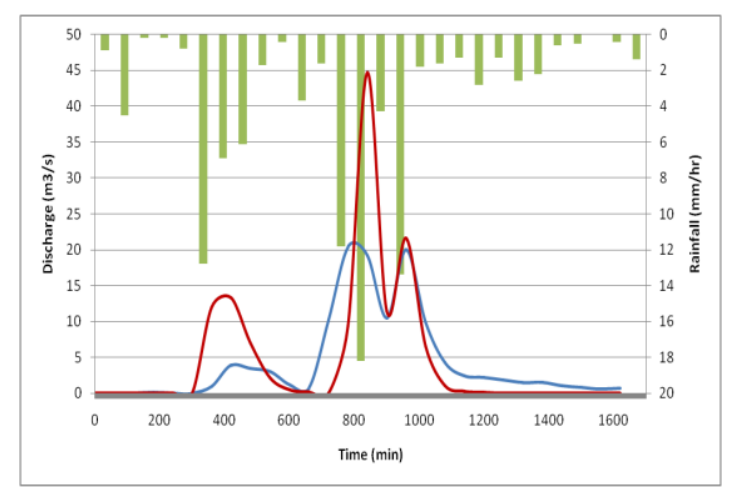

(f)

Rainfali Intensity, $\quad$ Observed Runoff, $\quad$ Simulated Runoff

Figure 4: Observed and simulated hydrographs of calibrated rainfall events of Harsul watershed (a) July 26, 1997; (b) July 27,1997;(c) August 4,1997;(d) August 21,1997;(e) August 22,1997;(f)August 23,1997. 
Table 3: Model results for rainfall events of Harsul watershed

\begin{tabular}{|c|c|c|c|c|c|c|c|c|c|}
\hline \multirow{2}{*}{$\begin{array}{c}\text { Date of rainfall } \\
\text { event }\end{array}$} & \multicolumn{3}{|c|}{ Cumulative runoff (m3/s) } & \multicolumn{3}{|c|}{ Peak runoff (m3/sec) } & \multicolumn{3}{|c|}{ Time to peak runoff (min) } \\
\hline & Obs* & $\operatorname{Sim} * *$ & $\begin{array}{c}\text { Variation } \\
(\%)\end{array}$ & Obs & Sim & $\begin{array}{c}\text { Variation } \\
(\%)\end{array}$ & Obs & Sim & $\begin{array}{c}\text { Variation } \\
(\%)\end{array}$ \\
\hline July 26,1997 & 43.98 & 102.16 & 57 & 8.10 & 29.00 & 72 & 360 & 120 & 67 \\
\hline July 27,1997 & 65.85 & 54.18 & 18 & 8.50 & 18.10 & 53 & 780 & 180 & 77 \\
\hline August 4,1997 & 10.35 & 8.83 & 15 & 4.382 & 4.360 & 1 & 720 & 600 & 17 \\
\hline August 21,1997 & 2.96 & 20.70 & 86 & 1.50 & 10.51 & 86 & 660 & 360 & 45 \\
\hline August 22,1997 & 33.33 & 31.49 & 5 & 16.56 & 11.33 & 32 & 360 & 360 & 0 \\
\hline August 23,1997 & 120.62 & 138.36 & 13 & 20.40 & 44.73 & 54 & 780 & 840 & 7 \\
\hline
\end{tabular}

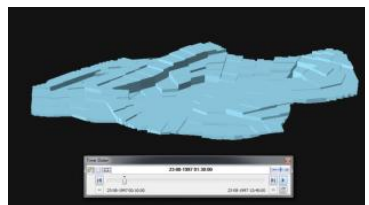

(a) $1 \mathrm{hr} 30 \mathrm{mins}$

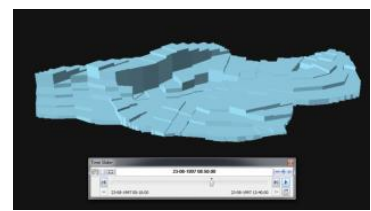

(b) $8 \mathrm{hr} 50 \mathrm{mins}$

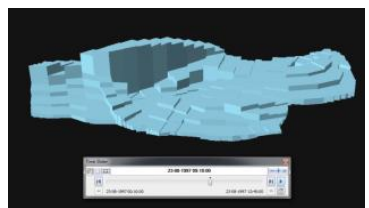

(c) $9 \mathrm{hr} 10 \mathrm{mins}$

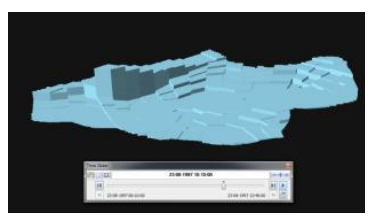

(e) $10 \mathrm{hr} 40 \mathrm{mins}$

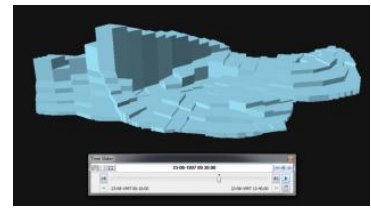

(d) $10 \mathrm{hr} 10 \mathrm{mins}$

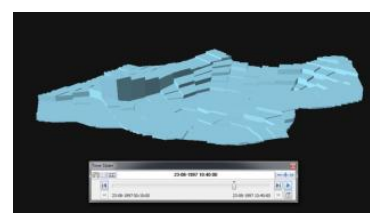

(h) $13 \mathrm{hr} 40 \mathrm{mins}$
Fig 5: Time series animation of runoff at different time intervals.

\section{CONCLUSIONS}

From the simulation results of all the rainfall events, it is seen that the variation of cumulative runoff is within $5 \%$ to $86 \%$, the peak runoff variation is between $1 \%$ to $86 \%$ and time to peak runoff $0 \%$ to $77 \%$. The study shows that Nash objective function is efficient in maintaining the time of the peak runoff and shape of the simulated hydrograph similar to the observed hydrograph. However, for cumulative runoff it showed good results for some of the events except those which have high rainfall intensity and low runoff. The study has shown that the Genetic Algorithm is a useful search technique in calibrating rainfall-runoff models and runoff prediction.The application of GIS in visualizing the runoff in the form of 3D time series animations can help researchers and scientists to better analyze the runoff behaviour at any point in the watershed area.

\section{REFERENCES}

[1] Agrawal, R. K., and J. K. Singh (2003). "Application of a Genetic Algorithm in the Development and Optimisation of a Non-linear Dynamic Runoff Model." Biosystem Engineering, 86 (1), 87-95.

[2] Nourani, V. (2008) "A Comparative Study on Calibration Methods of Nash's Rainfall-Runoff Model to Ammameh Watershed, Iran.", Journal of Urban and Environmental Engineering, 2 (1), 14-20.

[3] Servat, E., and Alain, D. (1991). "Selection of Calibrated Objective Functions in Context of Rainfall-Runoff Modelling in a Sundanese Savannah Area.", Hydrological Sciences Journal, 36, 307-330.

[4] Reddy, K. Venkata, T. I. Eldho, E. P. Rao, and A. T. Kulkarni (2011). "FEM-GIS Based Channel Network Model for Runoff Simulation in Agricultural Watersheds Using Remotely Sensed Data.", International Journal of River Basin Management 9(1), 17-30. 